\title{
Effects of Caffeine on Colon: A Potential Clinical Use of Coffee in Surgical Patients
}

\author{
Anna Vittoria Mattioli Milena Nasi Alberto Farinetti Roberta Gelmini \\ Department of Surgical, Medical and Dental Department of Morphological Sciences Related to Transplant, \\ Oncology and Regenerative Medicine (University of Modena and Reggio Emilia), Modena, Italy
}

Dear Editor,

We have read with great interest the paper "Effect of Caffeine Intake on Postoperative Ileus: A Systematic Review and Meta-Analysis and Muscle Breakdowns" by Gkegkes et al. [1], and we found his manuscript of importance with a view to clinical prevention. The paper reviewed the available evidence concerning the postoperative administration of coffee in enhanced recovery in the postoperative period. They concluded that the use of coffee can change the way to enhance recovery after surgery.

With reference to the findings reported in the paper, we would like to make the following contribution to the discussion. Caffeine exerts several effects both on cardiovascular and gastrointestinal systems [2]. Caffeine seems to have anti-inflammatory consequence mediated by antagonistic effects on $\mathrm{A} 2 \mathrm{~A}$ receptors on immune cells, such as $\mathrm{T}$ and $\mathrm{B}$ cells and macrophages [3-5]. In addition, studies in human and animal cell models showed a de- creased production of the principal proinflammatory cytokines when treated with caffeine. Coffee is considered to be the world's most widely consumed pharmacological substance. More than $90 \%$ of United States adults report consuming caffeine on a daily basis.

Coffee contains many different components other than caffeine, that is, phenolic antioxidants principally of chlorogenic acids (CGAs). Coffee polyphenols possess anticarcinogenic and antihypertensive properties, as well as hypoglycemic and hypolipidemic effects $[2,3]$. CGAs acts as nutraceutical and food additives, making such molecules good candidates for the formulation of dietary supplements and functional foods $[5,6]$. Coffee consumption has also been associated with high longevity and a low incidence of various degenerative and nondegenerative diseases in epidemiological studies [2, 4]. Regarding the bioavailability of CGAs, approximately one- third of the ingested amount via coffee consumption can be absorbed in the human gastrointestinal tract and metabolized [2, 5].

Gkegkes et al. [1] referred that pathophysiology concerning postoperative ileus is poorly defined and dependent on a multitude of factors; the most important of which are inflammation, the effects of surgical manipulation, administration of opioids, autonomic dysfunction, and deregulation of the gastrointestinal hormone activity and electrolyte fluctuations. Caffeine acts positively on inflammation and promotes nitric oxide synthesis in the endothelium by the release of $\mathrm{Ca} 2$ from the endoplasmic reticulum through activation of the ryanodinesensitive $\mathrm{Ca} 2$ channel and the suppression of cyclic guanosine monophosphate degradation in the isolated rat aorta, resulting in the caffeine-induced augmentation of endothelium-dependent vasodilatation. Caffeine effects vary among
KARGER

(c) 2019 S. Karger AG, Basel

karger@karger.com

www.karger.com/dsu
Prof. Anna Vittoria Mattioli

Department of Surgical, Medical and Dental Department of Morphological Sciences Related to Transplant, Oncology and Regenerative Medicine

University of Modena and Reggio Emilia, Via del pozzo, IT-71 41100 Modena (Italy)

E-Mail annavittoria.mattioli@unimore.it 
individuals. An important contributor to variability relates to the fact that individuals habituate and become tolerant to many of its physiological effects. Nonhabitual coffee consumers do not develop tolerance thereby typically experiencing the compound's effects at lower levels of dietary intake when consumed. Clinically, the postoperative administration of coffee reduces time to first bowel movement $[1,4,7]$. This has important clinical and economic consequences in major abdominal surgery [7].

\section{References}

1 Gkegkes ID, Minis EE, Iavazzo C. Effect of Caffeine Intake on Postoperative Ileus: A Systematic Review and Meta-Analysis and Muscle Breakdowns. Dig Surg. DOI: 10.1159/ 000496431.

2 Mattioli AV. Effects of caffeine and coffee consumption on cardiovascular disease and risk factors. Future Cardiol. 2007 Mar;3(2): 203-12.

3 Joós G, Jákim J, Kiss B, Szamosi R, Papp T, Felszeghy S, et al. Involvement of adenosine
Caffeine, in moderate daily doses of 300 $\mathrm{mg}$, or 3 cups of coffee, appears to be safe and harmless for healthy adults [2].

It can be concluded that the use of coffee in the postoperative Ileus can be useful and safe.

\section{Disclosure Statement}

The authors have no conflicts of interest to declare.

A3 receptors in the chemotactic navigation of macrophages towards apoptotic cells. Immunol Lett. 2017 Mar; 183:62-72.

4 Farinetti A, Zurlo V, Manenti A, Coppi F, Mattioli AV. Mediterranean diet and colorectal cancer: A systematic review. Nutrition. 2017 Nov - Dec;43-44:83-8.

5 Mattioli AV, Bonatti S, Melotti R, Mattioli G. Atrial stunning, inflammation and nutritional status after cardioversion from atrial fibrillation. Int J Cardiol. 2008 Oct 13;129(3):344-7.

\section{Funding Source}

None.

\section{Authors' Contribution}

M.N., A.V.M., A.F. and R.G.: contributed to the study's concept. A.V.M. and M.N.: contributed to writing the article; all authors contributed to the critical review of the article.
6 Mattioli AV, Migaldi M, Farinetti A. Coffee in hypertensive women with asymptomatic peripheral arterial disease: a potential nutraceutical effect. J Cardiovasc Med (Hagerstown). 2018 Apr;19(4):183-5.

7 Zhuang CL, Ye XZ, Zhang CJ, Dong QT, Chen BC, Yu Z. Early versus traditional postoperative oral feeding in patients undergoing elective colorectal surgery: a meta-analysis of randomized clinical trials. Dig Surg. 2013; 30(3):225-32. 